\title{
Incidental White Matter Lesions Identified on Magnetic Resonance Images of Normal Japanese Individuals
}

\section{-Correlation with Age and Hypertension-}

\author{
Hirofumi OYAMA, Yoshihisa KIDA, Takayuki TANAKA, \\ Takanori IWAKOSHI, Masahiro NIWA, and Tatsuya KOBAYASHI \\ Department of Neurosurgery, Komaki City Hospital, Komaki, Aichi
}

\begin{abstract}
Incidental white matter high-intensity lesions are frequently seen on $T_{2}$-weighted magnetic resonance (MR) images of the brain in older people. The incidence increases with advancing age or hypertension. Brain MR images of 59 normal individuals were examined to analyze this phenomenon. The total number of white matter high-intensity lesions correlated significantly with age $(\mathrm{p}=0.004)$ or systolic blood pressure $(\mathrm{p}=0.03)$. The 60 - to 69 -year-old group demonstrated a very close correlation of white matter lesions with systolic $(p=0.02)$ and diastolic blood pressure $(p=0.01)$, in contrast to the 50 - to 59-year-old group. Hypertensive subjects in their 60s are thought to develop more white matter lesions than subjects in their 50s.
\end{abstract}

Key words: white matter lesion, magnetic resonance imaging, age, hypertension

\section{Introduction}

Brain examinations are now based on magnetic resonance (MR) imaging or MR angiography, especially for brain tumors, aneurysms, or stenoses of cerebral arteries. A frequent incidental finding is white matter high-intensity lesions on $\mathbf{T}_{2}$-weighted MR images in older people.

Incidental white matter lesions are correlated with many factors such as prior brain ischemia, ${ }^{2)}$ cardiac disease, ${ }^{7}$ diabetes mellitus, hypercholesterolemia, ${ }^{10,11,14)}$ advancing age, and hypertension. ${ }^{2,5,9-11,14)}$ This study analyzed the correlation with age and hypertension in normal individuals with no other risk factors.

\section{Subjects and Methods}

Fifty-nine normal individuals admitted to our clinic for routine brain examination with no risk factors were included in this study. There were 38 males and 21 females.

Axial $T_{2}$-weighted MR images ( $7.5 \mathrm{~mm}$ thick) were

Received August 17, 1993; Accepted December 8, 1993 obtained with the spin echo technique (repetition time [TR] $2500 \mathrm{msec}$, echo time [TE] $100 \mathrm{msec}$ ) using a 1.5 T superconducting magnet (Signa; General Electric Medical Systems, Milwaukee, Wis., U.S.A.). All high-intensity lesions in all slices were classified into six groups of $0-2.7,2.8-5.4,5.5-8.1,8.2-10.8$, 10.9-13.5, and $13.6-16.2 \mathrm{~mm}$ according to the greatest diameter (Fig. 1). The blood pressure and blood chemistry were examined in 55 subjects.

Correlations of the number of high-intensity le sions with age and systolic or diastolic blood pressure were analyzed with the Spearman's rank correlation coefficient method. $P$ values of $<0.05$ were considered statistically significant.

\section{Results}

Figure 2 shows the distribution of age, systolic and diastolic blood pressure, and number of lesions among the subjects. The number of white matter high-intensity lesions was significantly correlated with age (correlation coefficient $0.38, p=0.004$ ) and systolic blood pressure (correlation coefficient 0.3 , $\mathrm{p}=0.03$ ) (Fig. 3). Although the diastolic blood pressure was also correlated (correlation coefficient $0.22)$, it was not significant $(\mathrm{p}=0.11)$. 


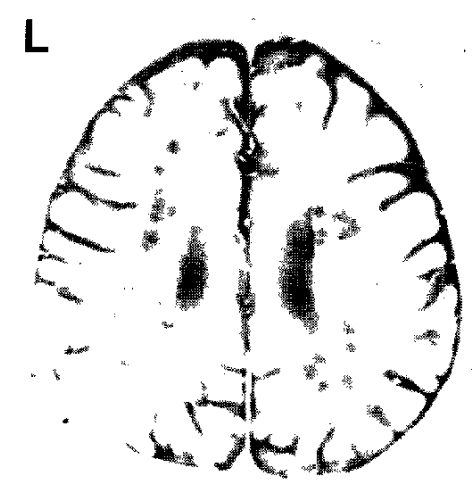

Fig. 1 Representative $\mathrm{T}_{2}$-weighted MR image (TR $2500 \mathrm{msec} / \mathrm{TE} 100 \mathrm{msec}$ ), showing incidental high-intensity lesions of various sizes in the white matter.
The correlation of white matter lesions with blood pressure was assessed for the 50- to 59-year-old (21 subjects) and 60- to 69-year-old groups (24 subjects). In the 60- to 69-year-old group, a very close correlation with systolic (correlation coefficient $0.49, \mathrm{p}=$ 0.02 ) or diastolic blood pressure (correlation coefficient $0.52, \mathrm{p}=0.01$ ) was found, in contrast to the 50- to 59-year-old group (Fig. 4). 0- to 2.7-mmsized lesions occurred most frequently in the 50 - to 59-year-old group (mean number 37.7 ) and the 60- to 69-year-old group (mean 38.9) (Fig. 5).

Systolic blood pressure increased significantly with diastolic blood pressure (correlation coefficient 0.56 , $\mathrm{p}=0.0001)$ and tended to increase with age (correlation coefficient $0.21, p=0.12$ ) (data not shown). The occurrence of white matter lesions did not correlate with total cholesterol, high-density lipoprotein, triglyceride, or $\beta$-lipoprotein levels in the blood (data not shown).
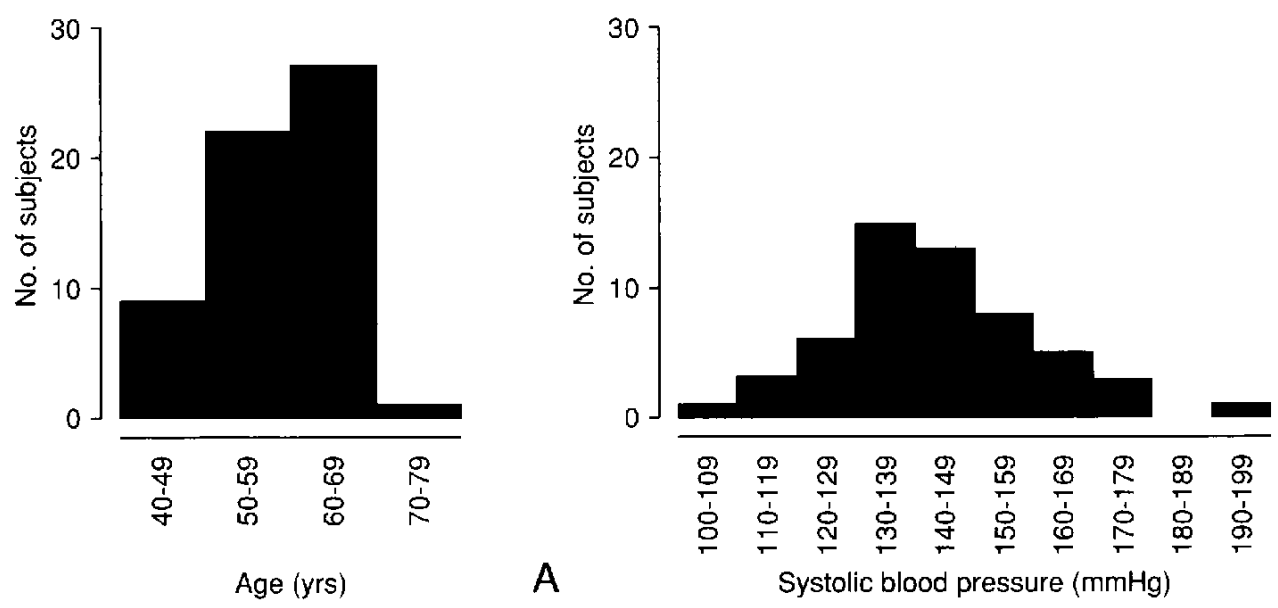

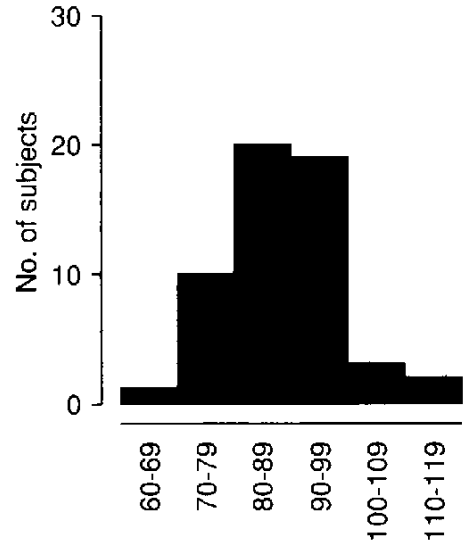

Diastolic blood pressure $(\mathrm{mmHg})$
A

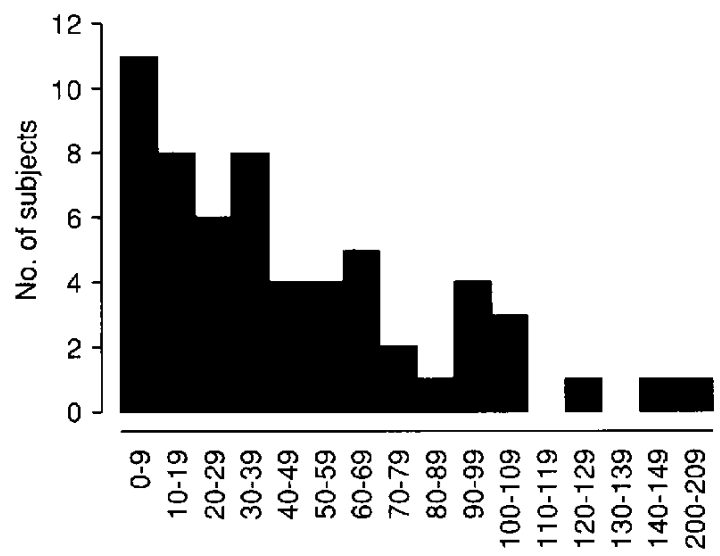

No. of white matter lesions

Fig. 2 Histograms of age (A), systolic blood pressure (B), diastolic blood pressure (C), and number of white matter lesions (D) in the subjects. 

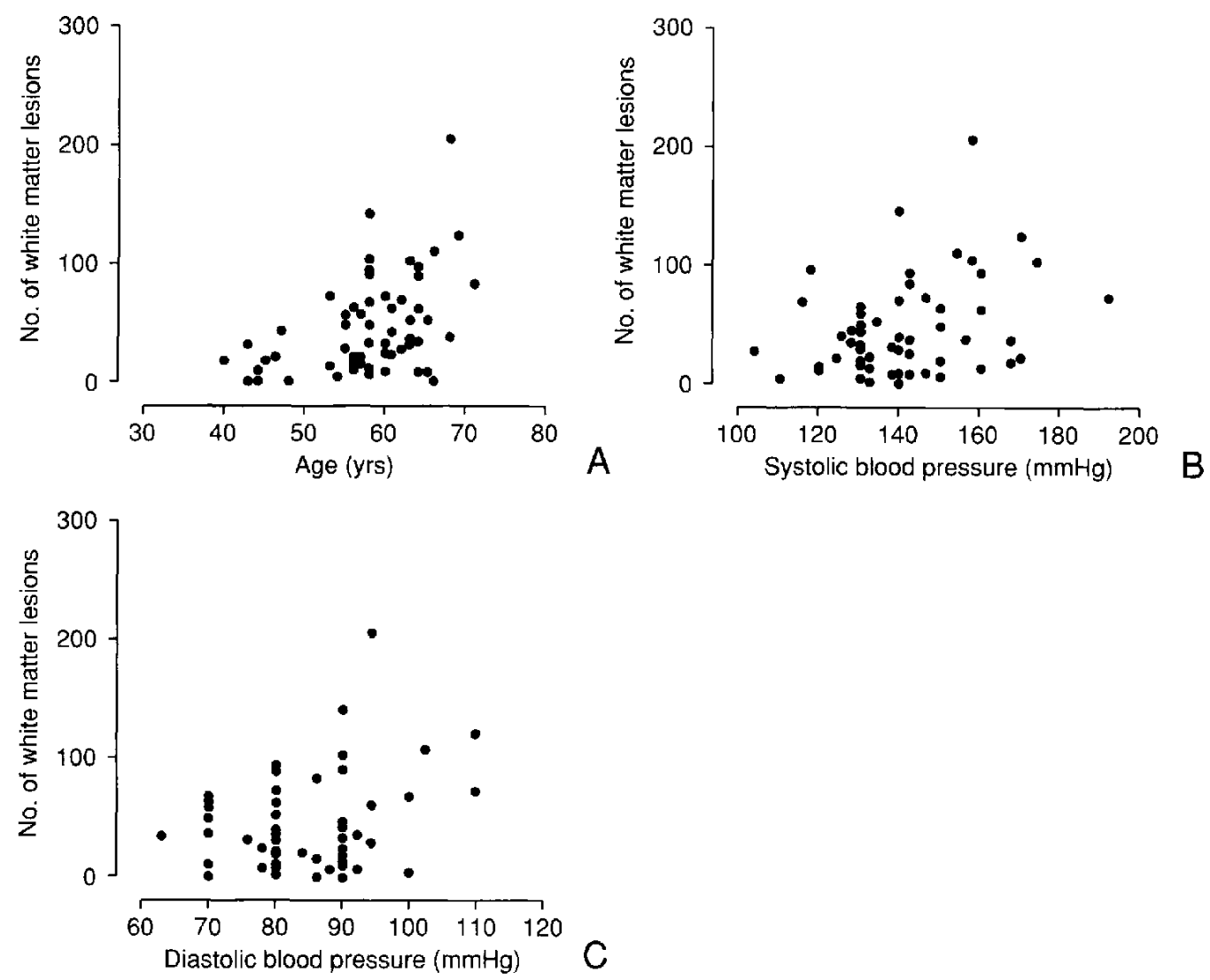

Fig. 3 Distribution charts, showing that the number of white matter lesions correlates significantly with age (A: correlation coefficient $0.38, \mathrm{p}=0.004)$ and systolic blood pressure $(\mathrm{B}$ : correlation coefficient $0.3, \mathrm{p}=0.03$ ), and a slight correlation with diastolic blood pressure (C: correlation coefficient $0.22, \mathrm{p}=0.11$ ).

\section{Discussion}

The incidence of incidental white matter MR imaging lesions increases with age and correlates with both high systolic blood pressure $(>160 \mathrm{mmHg})$ and high diastolic blood pressure ( $>100 \mathrm{mmHg}$ )., ${ }^{2,(1)}$ Our data confirmed these correlations. We also found that hypertensive subjects in their $60 \mathrm{~s}$ tended to demonstrate more white matter lesions than subjects in their $50 \mathrm{~s}$. The brain vessels of older subjects may already have deteriorated due to the aging process and might be more susceptible to hypertension. As the systolic blood pressure is weakly correlated with age, it is difficult to discuss the influence of age and hypertension separately.

The pathological process causing incidental white matter lesions is generally thought to be degeneration of myelinated axons and gliosis. The lesions represent incomplete ischemia without infarction because of the absence of cavitation and resolving necrosis. ${ }^{6,15)}$ As dilated perivascular spaces with vascular ectasia can also appear as high-intensity lesions on $\mathrm{T}_{2}$-weighted MR images, ${ }^{17}$ discrimination between degeneration and vascular ectasia is very difficult based only on MR images. Probably our subjects demonstrated both types of lesion. However, both types of lesion are caused by arteriosclerosis or hyaline arteriolosclerosis, which is one of the most common degenerative changes in brain vessels, and increases with advancing age and hypertension. . $^{1,3,8,13,15,17,20)}$

Cerebral blood flow (CBF) is known to decrease gradually and progressively with increasing age $^{4,12,16,18,19,21)}$ and is accelerated by risk factors such as hypertension, heart disease, diabetes mellitus, and hyperlipidemia. ${ }^{18,19]}$ This study did not measure $\mathrm{CBF}$, so further examination is necessary to investigate the relationship between the occurrence of incidental white matter high-intensity lesions on $T_{2}$ weighted MR images and decreased CBF. 

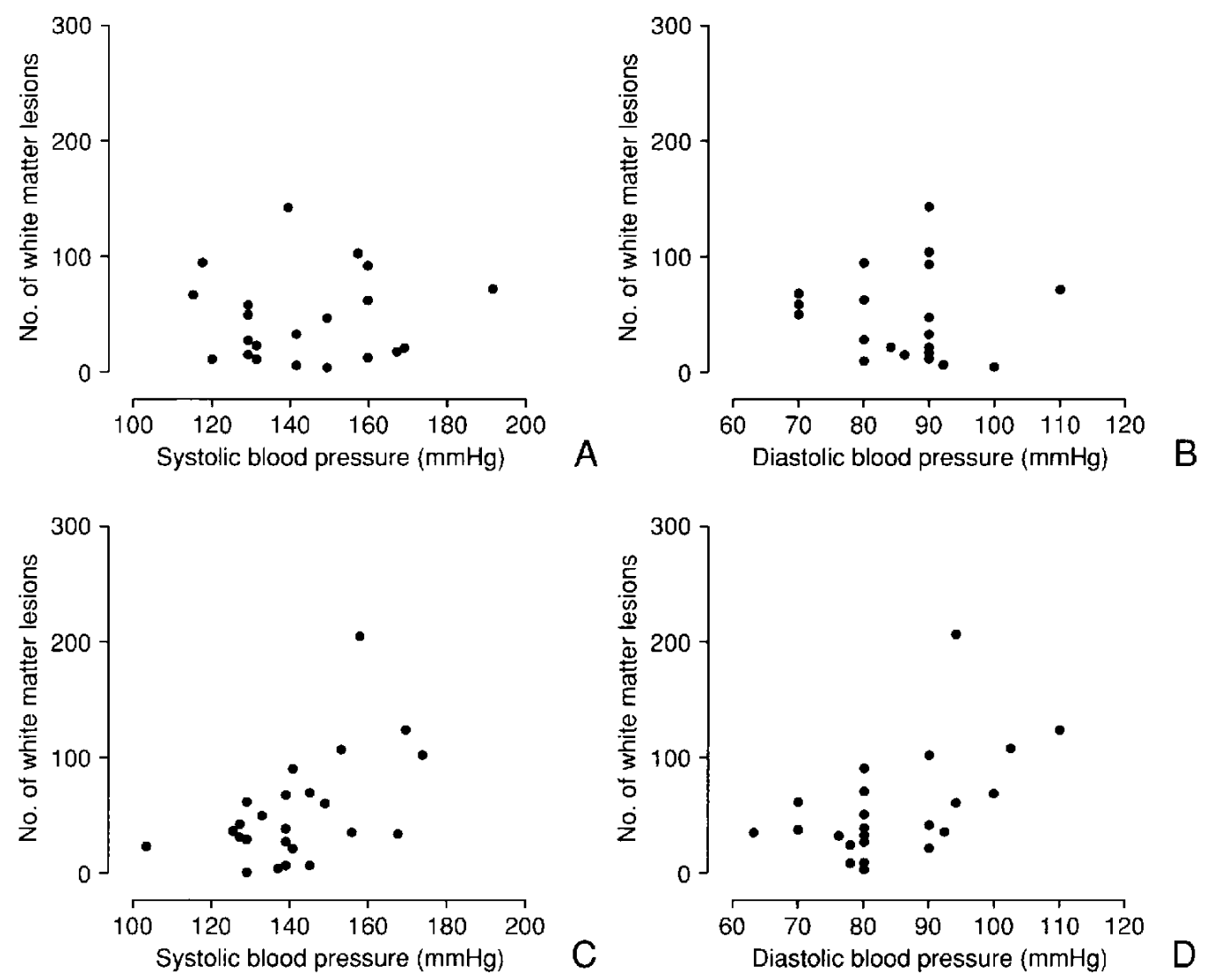

Fig. 4 Distribution charts of the 50- to 59-year-old group, showing that the number of white matter lesions does not correlate with systolic blood pressure (A: correlation coefficient $0.0003, p=0.99$ ) or diastolic blood pressure (B: correlation coefficient $-0.23, \mathrm{p}=0.31$ ). Distribution charts of the 60- to 69-year-old group, showing that the number of white matter lesions correlates significantly with both systolic (C: correlation coefficient $0.49, \mathrm{p}=0.02$ ) and diastolic blood pressure (D: correlation coefficient $0.52, \mathrm{p}=0.01$ ).

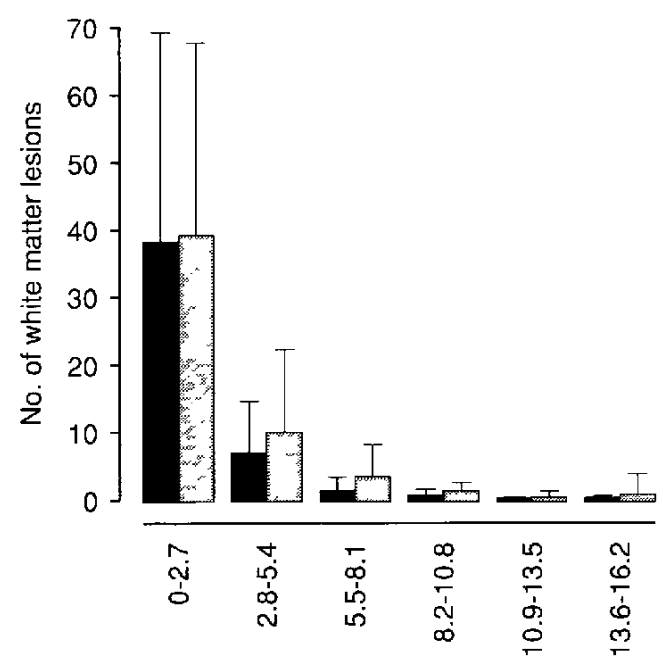

Diameter of white matter lesion $(\mathrm{mm})$

\section{References}

1) Awad IA, Johnson PC, Spetzler RF, Hodak JA: Incidental subcortical lesions identified on magnetic resonance imaging in the elderly. II. Postmortem pathological correlations. Stroke 17: 1090-1097, 1986

2) Awad IA, Spetzler RF, Hodak JA, Awad CA, Carey $\mathrm{R}$ : Incidental subcortical lesions identified on magnetic resonance imaging in the elderly. I. Correlation with age and cerebrovascular risk factors. Stroke

Fig. 5 The number of white matter lesions of each size in the 50- to 59-year-old (solid columns, $\mathrm{n}=$ 22) and 60- to 69-year-old groups (shaded columns, $\mathrm{n}=27$ ). The columns show the mean number of white matter lesions and the bar shows the SD. 
17: 1084-1089, 1986

3) Bell ET, Clauson BJ: Primary (essential) hypertension: A study of four hundred and twenty cases. Arch Path (Chicago) 5: 939-1002, 1928

4) Braffman BH, Zimmerman RA, Trojanowski JQ, Gonatas NK, Hickey WF, Schlaepfer WW, Brain MR: Pathologic correlation with gross and histopathology. 2. Hyperintense white-matter foci in the elderly. AJNR 9: 629-636, 1988

5) Brant-Zawadzki M, Fein G, Dyke CV, Kiernan R, Davenport L, Groot JD: MR imaging of the aging brain: Patchy white-matter lesions and dementia. AJNR 6: 675-682, 1985

6) Brun A, Englund E: A white matter disorder in dementia of the Alzheimer type: A pathoanatomical study. Ann Neurol 19: 253-262, 1986

7) Fazekas F, Niederkorn K, Schmidt R, Offenbacher $\mathrm{H}$, Horner S, Bertha G, Lechner $\mathrm{H}$ : White matter signal abnormalities in normal individuals: Correlation with carotid ultrasonography, cerebral blood flow measurements, and cerebrovascular risk factors. Stroke 19: 1285-1288, 1988

8) Gamble CN: Pathogenesis of hyaline arteriosclerosis. Am J Pathol 122: 410-420, 1986

9) George AE, Leon MJD, Kalnin A, Rosner L, Goodgold A, Chase N: Leukoencephalopathy in normal and pathologic aging: 2. MRI of brain lucencies. AJNR 7: 567-570, 1986

10) Gerard G, Weisberg LA: MRI periventricular lesions in adults. Neurology 36: 998-1001, 1986

11) Kertesz A, Black SE, Tokar G, Benke T, Carr T, Nicholson L: Periventricular and subcortical hyperintensities on magnetic resonance imaging. Arch Neurol 45: 404-408, 1988

12) Kety SS: Human cerebral blood flow and oxygen consumption as related to aging. $J$ Chronic Dis 3: 478486,1956

13) Kirkpatrick JB, Hayman LA: White-matter lesions in MR imaging of clinically healthy brains of elderly sub- jects: Possible pathologic basis. Radiology 162: 509511,1987

14) Lechner $H$, Schmidt R, Bertha G, Justich E, Offenbacher $\mathrm{H}$, Schneider G: Nuclear magnetic resonance image white matter lesions and risk factors for stroke in normal individuals. Stroke 19: 263-265, 1988

15) Marshall VG, Bradley WG, Marshall CE, Bhoopat T, Rhodes RH: Deep white matter infarction: Correlation of MR imaging and histopathologic findings. Radiology 167: 517-522, 1988

16) Melamed E, Lavy S, Bentin S, Cooper G, Rinot Y: Reduction in regional cerebral blood flow during normal aging in man. Stroke 11: 31-35, 1980

17) Moritz AR, Oldt MR: Arteriolar sclerosis in hypertensive and non-hypertensive individuals. Amer $J$ Path 13: 679-728, 1937

18) Naritomi H, Meyer JS, Sakai F, Yamaguchi F, Shaw $T$ : Effects of advancing age on regional cerebral blood flow: Studies in normal subjects and subjects with risk factors for atherothrombotic stroke. Arch Neurol 36: 410-416, 1979

19) Shaw TG, Mortel KF, Meyer JS, Rogers RL, Hardenberg J, Cutaia MM: Cerebral blood flow changes in benign aging and cerebrovascular disease. Neurology 34: 855-862, 1984

20) Smith JP: Hyaline arteriolosclerosis in the kidney. $J$ Path Bact 69: 147-168, 1955

21) Yamaguchi F, Meyer JS, Yamamoto M, Sakaki F, Shaw T: Non-invasive regional cerebral blood flow measurements in dementia. Arch Neurol 37: 410-418, 1980

Address reprint requests to: H. Oyama, M.D., Department of Neurosurgery, Komaki City Hospital, 1-20 Joubushi, Komaki, Aichi 485, Japan. 